\title{
Infrared thermography online 1D and offline 2D evaluation of mechanical properties at cycling fatigue testing
}

\author{
by J. Tesař, M. Švantner*, J. Skála*, M. Novák** \\ * University of West Bohemia, New Technologies - Research Center, Univerzitní 8, Plzeň, Czech Republic, \\ tesar@ntc.zcu.cz, msvantne@ntc.zcu.cz, jskala@ntc.zcu.cz \\ ${ }^{* *}$ Research and Testing Institute Plzeň, Plzeň, Czech Republic, novak@vzuplzen.cz
}

\begin{abstract}
Mechanical testing and cyclic fatigue testing belong to the important material examinations. Standard methods are demanding to time and number of identical samples is needed. Thermographic methods have ambitions to shorten the testing time using only a few samples undergoing cyclic loading. A stepwise cyclic loading was applied to two cylindrical samples from 15Ch2NMFA steel. The temperature of tested samples was measured during the testing with increasing loading force using infrared camera. An online 1D and offline 2D evaluation of fatigue limit is introduced in this contribution. The results of fatigue limit evaluated with standard method and thermographic methods (1D and 2D) are compared and proved good agreement between methods.
\end{abstract}

\section{Introduction}

Fatigue fractures can occur in the material during its long-time cyclic loading, even if the load is below its yield strength. The fatigue lifetime depends on a loading force, frequency and time (i.e. number of cycles). There are many methods of evaluation of fatigue limit testing. Standard methods calculate with cycles to failure $\mathrm{N}$ (number of cycles to fracture) and with magnitude of a cyclic stress $S$ (applied load). Thermographic methods are based on surface temperature trend evaluation of the tested sample in dependence on applied load and/or time. Among basic standard methods belongs method using S-N curve (also known as Wöhler curve) [1]. Each value of S-N curve is generated by one sample measurement. Disadvantage of this method is its time consuming character (up to $10^{7}$ cycles per sample) and usually the need of at least 12 identical samples.

Thermographic methods have ambitions to shorten the testing time. As the mechanical energy is changed to thermal energy causing increase of temperature during the cyclic loading, the infrared thermography can be used for fatigue testing. Origins of thermographic methods focused on fatigue limit measurement were introduced in 1990's [2]. There it was shown that the temperature of loaded specimens increases at a rate determined by the applied load and number of cycles. Two main methods were developed according to previous research [3][4].

The Method 1 consists of making various constant amplitude fatigue tests with stresses higher than fatigue limit and for its determination uses temperature difference values [3]. The method 1 was used in [5] or [6] for standard flat AISI 304 stainless steel sample and welded/heat treated tubular specimens of carbon steel 1018 testing. A different approach of the method is based on a stepped loading procedure in which sample is gradually loaded, without interruptions, at different stress levels that are higher than the presumed fatigue limit values. Only one sample is used in this case.

The Method 2 consists of a stepped loading procedure which starts from loading levels lower than expected value of fatigue limit that is obtained as an intersection of a linear approximation of the first and second stage of the temperature increase[4]. This method was used for cast iron testing [7] and XC55 steel testing in [8][9].

A lot of modified thermographic methods were developed. An accelerated thermographic method based on gradually increasing loading test was introduced in [10] using only 3 samples of $\mathrm{X} 5 \mathrm{CrNi18-10}$ steel. The results were compared with standard Staircase method (35 samples), standard S-N curve determination method (18 samples) and thermographic camera mean temperature measurement during testing in constant amplitude loading conditions (12 samples) with $5 \%$ difference. An iteration method for the thermographic determination of fatigue limit in Fe 510 steel sample was presented in [13]. During experiment was used loading symmetry $R=-1$ (tension-compression) with frequency of $100 \mathrm{~Hz}$ and sample surface was homogenized with a thin opaque black paint layer for an increased emissivity. Authors defined two areas - the first area of interest out of the sample for the mean ambient temperature and the second for the maximal sample temperature and their difference was used for evaluation. A high speed IR camera was used for analysis of fatigue behavior Co-Cr based superalloy during mechanical fatigue tests in [11]. The average temperature from the central part of sample was recorded with frequency of $120 \mathrm{~Hz}$. So high recording frequency in comparison with loading force frequency $20 \mathrm{~Hz}$ allows to capture thermoelastic effect (temperature evolution during one loading period). Robust thermographic data analysis to fatigue limit evaluation of various martensitic stainless steels was performed in [12]. A graphical version of Method 2 was used for fatigue limit evaluation and data filtering and reference unloaded object with high emissivity sprayed surface was presented. Infrared thermography methods for fatigue life prediction of AZ31B magnesium alloy welds were used in [13], lock-in method for fatigue limit of steel welded joint specimen was evaluated in [14].

Most of the previous mentioned contributions work with single value as a result of selected area analysis (maximal or average temperature) per recorded image. Time evolution of these results in dependence on loading 
force/stress is subsequently created. In case of stepwise character of loading one temperature value per step is calculated with averaging. This time dependent procedure causes that most of the research regarding fatigue limit evaluation by infrared thermography has been focused on a measured data post-processing.

An online 1D evaluation method created at our laboratories based on above mentioned Method 2 was introduced in [15]. 2D thermographic method is introduced in this article as an extension of 1D method. One value of temperature difference or result of selected area analysis is replaced with a matrix of corresponding values of the whole sample and its closest surroundings. The evaluation procedure remains the same as in 1D with the difference that it is applied to the set of matrices. Therefore the result is a $2 \mathrm{D}$ field of values of fatigue limits for each pixel belonging to the selected area.

\section{Experimental setup and measurement}

Two standardized cylindrical specimens of $10 \mathrm{~mm}$ diameter from 15Ch2NMFA steel were used for fatigue measurement experiments. High emissivity paint with emissivity value of 0.93 in LWIR range [16] was applied to the central part of samples before testing - see figure 1. Samples were painted during turning around to avoid of paint splashing.

a)

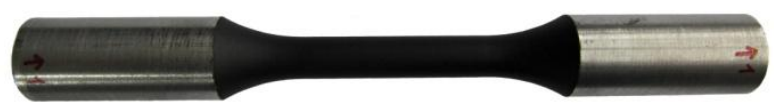

b)

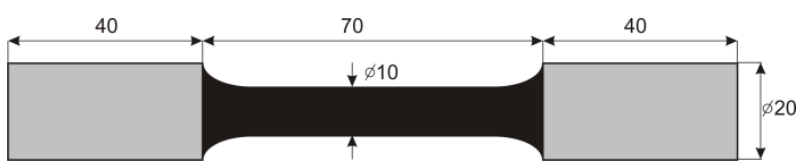

Fig. 1: Tested specimen - Sample 1: a) photo, b) sketch with dimensions in $\mathrm{mm}$.

A fatigue testing device SCHENCK was used for generating asymmetric sinusoidal loading force (R0.1 - the minimal load corresponds to $10 \%$ of the maximal load) with frequency of $10 \mathrm{~Hz}$. The load amplitude for sample 1 started with force of $10 \mathrm{kN}$ resp. $30 \mathrm{kN}$ for sample 2 (corresponding to the load of $127.3 \mathrm{MPa} ; 382.0 \mathrm{MPa}$ ) with equidistant step of $2 \mathrm{kN}(25.5 \mathrm{MPa})$ up to the rupture. Each loading step took approximately 10 minutes (due to temperature stabilization).

IR camera Optris PI400 was used for the noncontact temperature measurement during sample cyclic loading. It is an uncooled micro-bolometric camera equipped with FPA detector (Focal Plane Array) with resolution of $382 \times 288$ pixels, which measures in the wavelength range from $7.5 \mu \mathrm{m}$ to $13 \mu \mathrm{m}$. The measurement temperature range of the camera is from $-20{ }^{\circ} \mathrm{C}$ to $1500{ }^{\circ} \mathrm{C}$; the subrange from $-20^{\circ} \mathrm{C}$ to $100{ }^{\circ} \mathrm{C}$ was used. A telescopic lens with the field of view $13^{\circ} \times 10^{\circ}$ and the minimum focus distance $50 \mathrm{~cm}$ was used. A temperature sensitivity of the camera with telescopic lens is $0.1 \mathrm{~K}$ and its accuracy is $\pm 2{ }^{\circ} \mathrm{C}$ or $\pm 2 \%$. The maximum camera framerate is $80 \mathrm{~Hz}$, recording framerate $1 \mathrm{~Hz}$ was used as a sufficient frequency for this long term measurement (final duration more than 5 and a half hour for sample 1).

The IR camera was placed on a tripod in front of the fatigue test machine in distance of $0.5 \mathrm{~m}$. A tested sample was strengthened into the clamp jaws of the machine. A polystyrene slab was put down behind the sample to avoid reflections from the surroundings. The experimental arrangement is shown in figure 2.

a)

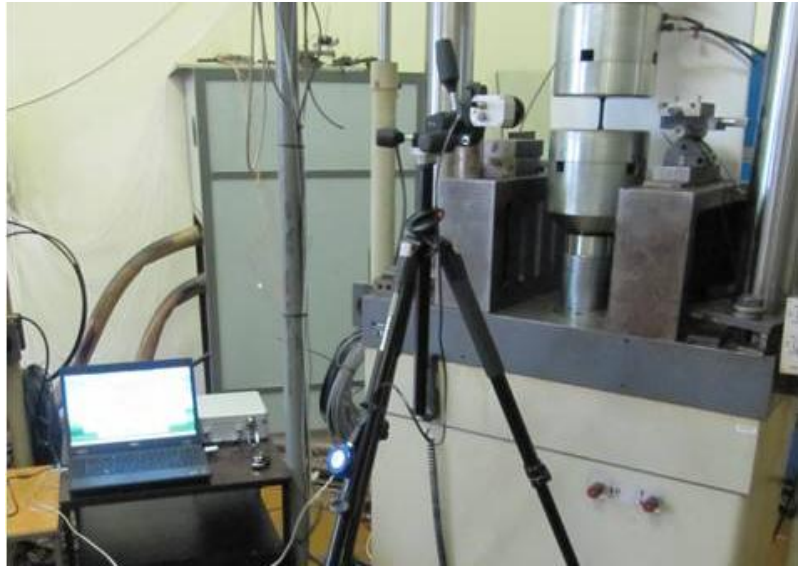

b)

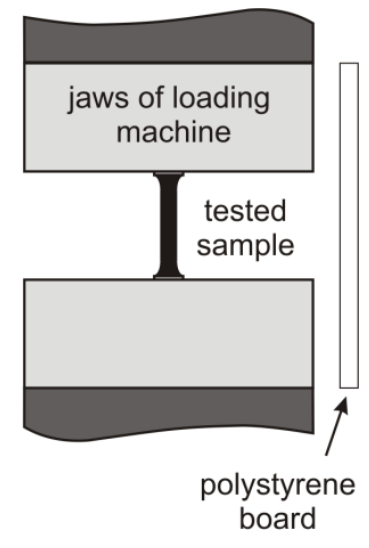

Fig. 2: Experimental arrangement - a) photo, b) sketch.

The experiment starts with settings of all parameters to the RIFT module of the LabIR® software that was used for IR measurement and online fatigue limit evaluation. The IR camera recording begins before the first step of loading force; each next loading force magnitude was higher than previous with the step of $2 \mathrm{kN}$ without any time delays between steps. Two analyzed rectangles were created at the IR image - a smaller one was placed on the sample body area for $1 \mathrm{D}$ evaluation and a larger rectangle was placed to the sample with its nearest surroundings - see figure 3. 

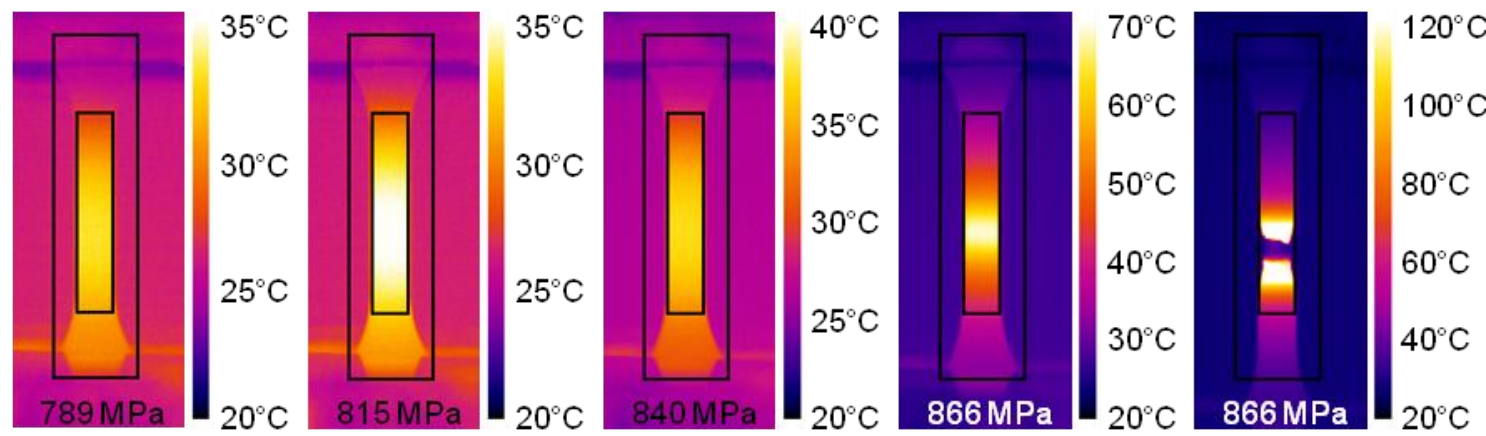

Fig. 3: IR image with rectangular areas for $1 D$ and $2 D$ fatigue limit evaluation during last phase of testing - applied load of $815 \mathrm{MPa}, 840 \mathrm{MPa}$ and $866 \mathrm{MPa}$ just before and after sample failure.

There is clearly seen from the temperature field of the sample at figure 3 that the temperature increase in the last period of the test is relative high. It is reached maximal temperature $33.3^{\circ} \mathrm{C}$ with load of $789 \mathrm{MPa}, 35.3^{\circ} \mathrm{C}$ with load of $815 \mathrm{MPa}, 37.2^{\circ} \mathrm{C}$ with load of $840 \mathrm{MPa}, 68.6^{\circ} \mathrm{C}$ with load of $866 \mathrm{MPa}$ just before rupture ( $1 \mathrm{~s}$ before) and $124.9^{\circ} \mathrm{C}$ immediately after the rupture (the temperature subrange of the camera is saturated). At the other side the exact position of the rupture cannot be predicted from IR images in longer period before than a few seconds before the failure. The reflection of heated sample body above and below the sample is visible at the upper and bottom jaws cylinder (both of jaws cylinders are without the high emissivity paint, so their emissivity value is very low corresponding to the shiny metal surface - see photo of jaws in figure 2).

\section{Evaluation}

Determination of fatigue limit was made by three methods - by standard method and by thermographic methods in 1D and 2D versions. Evaluation of fatigue limit by standard method using S-N curve was made by Research and Testing Institute laboratory in Plzeň.

1D thermographic method evaluation was made online by the RIFT module of LabIR® software, which was developed in our laboratories. The fatigue limit determination is based on the Method 2 mentioned above in Sec.1. The procedure of fatigue limit evaluation is same for both samples and it is presented for sample 1. A maximum temperature of a selected sample area is evaluated at each time step - see figure 4 a) and temperature dependence on load in figure 4 b).

a)

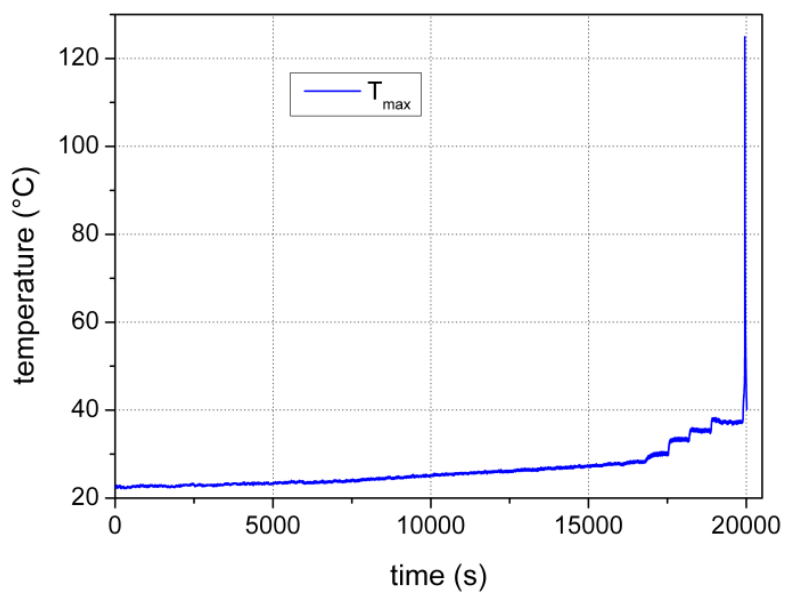

b)

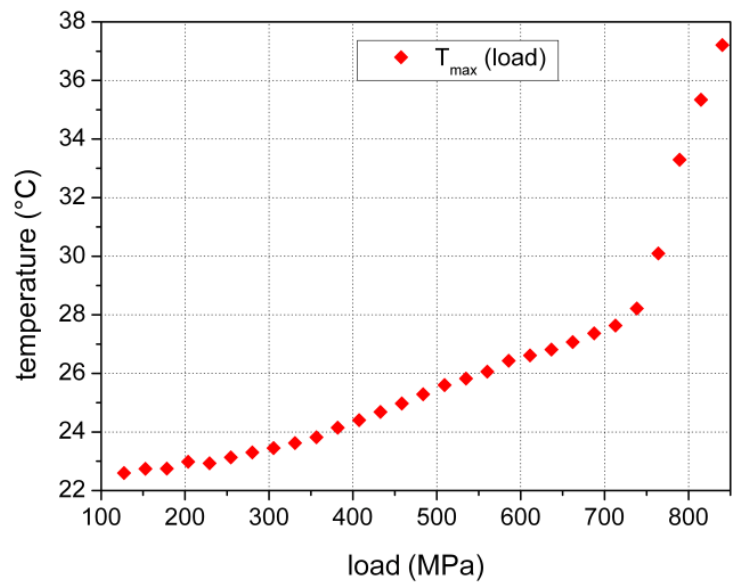

Fig. 4: a) Maximal temperature time evolution of analyzed rectangle placed to the tested sample body, b) the dependence of maximal temperature of each loading step on load corresponding to the set loading force to the machine.

The time evolution of analysed rectangle maximal temperature shown in figure 4 a) starts with very low increase up to time approx. $17000 \mathrm{~s}$ where the loading steps cannot be recognized. After this part the curve continues with stepwise character of temperature corresponding to the loading steps. The temperature time evolution ends with rapid temperature increase during sample failure up to $125^{\circ} \mathrm{C}$ and very quick sample cooling back to the temperature about $40^{\circ} \mathrm{C}$ after the sample rupture.

A temperature used for the fatigue limit evaluation is obtained by an averaging of maximal temperature values in a time interval of about 1 minute before the end of a loading step. Result temperature values obtained with this 
procedure in dependence on load are presented in figure $4 \mathrm{~b}$ ). The increase of temperature in dependence on applied load looks quite linear up to $720 \mathrm{MPa}$ with a little deflection and then there is big increase of temperature with loads higher than $740 \mathrm{MPa}$. This curve break corresponds to the change from elastic to plastic deformation accompanied by huge amount of heat releasing.

The fatigue limit evaluation is based on the stepwise distribution of measured values from figure $4 \mathrm{~b}$ ) into two groups - region A (loads lower than searched fatigue limit) and region B (loads higher than searched fatigue limit). The temperatures in both regions are linearly approximated. The correct distribution to regions $A$ and $B$ is ruled by the condition that the highest load in region $A$ is lower than fatigue limit and the lowest load in region $B$ is higher than the fatigue limit, that is calculated as intersection of region $A$ and $B$ linear approximation, see sketch of principle in figure 5 .

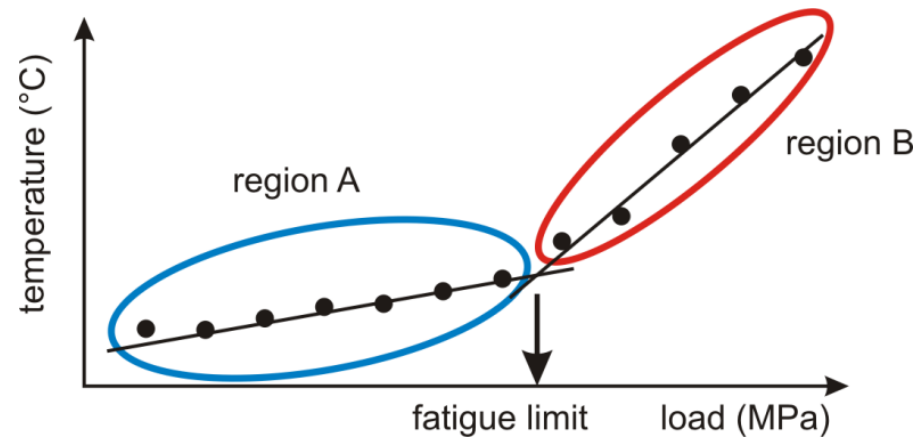

Fig. 5: The principle of Method 2 that is based on measured data distribution to regions $A$ and $B$.

This procedure - dividing into regions and checking of condition fulfilment is made with the software module automatically online after each step. The $1 \mathrm{D}$ evaluation can be made offline in post-processing due to IR image and data recording during the whole experiment too.

Two-dimensional (2D) thermographic method evaluation was made offline due to high computing requirements. A larger analyses rectangular area including surroundings of the sample was created in the IR image. Temperatures of each pixel from this area were time-averaged in the same time intervals as in 1D evaluation (1 minute before the end of each loading step). The set of matrices was evaluated in the same way as points in 1D method. The values out of the sample body were removed due to no physical reason.

\section{Results}

The fatigue limit determined by the previous measurement using standard method (S-N curve) was $464 \mathrm{MPa}$.

For thermographic evaluation was considered only data up to step number 23 with load of $687.5 \mathrm{MPa}$ because of the higher loads belong to the plastic deformation. In case when more than one distribution to regions $A$ and $B$ fulfils the condition about fatigue limit position between regions, the average value of partial results is considered as fatigue limit result.

The sample 1 evaluation is shown in figure 6 a) and b) as an example of 1D thermographic fatigue limit determination. There are two possibilities of distribution to regions $A$ and $B$ that fulfil the specified condition for sample 1 with evaluating loading steps from step number 1 (127.3 MPa) to step number $23(687.5 \mathrm{MPa})$.

a)

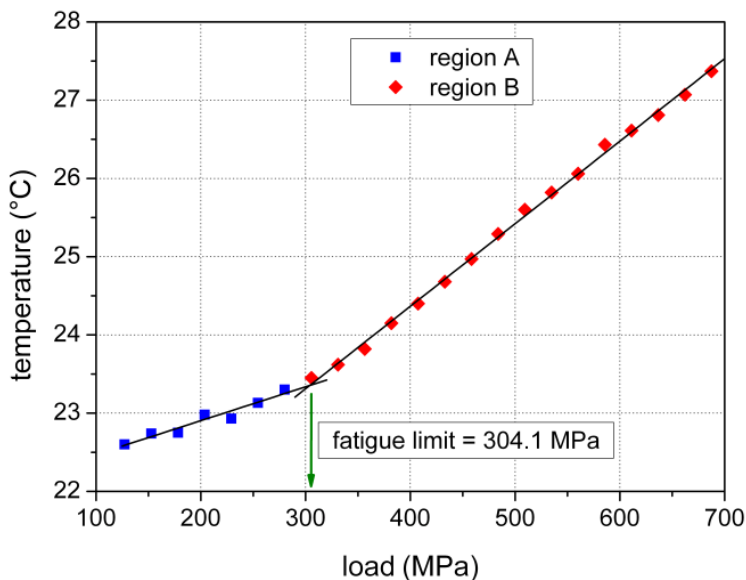

b)

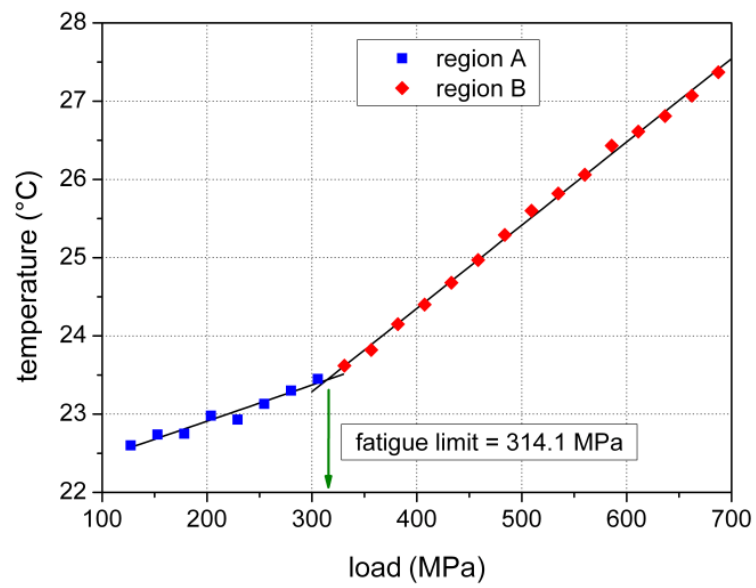

Fig. 6: Graphical presentation of fatigue limit evaluation for sample 1- step number 1 up to step 23: a) distribution to region $A$ (from step 1 to step 7) and $B(8 . .23)$ with result of $304.1 \mathrm{MPa}, b) A(1 . .8)$ and $B(9 . .23)$ with result of $314.1 \mathrm{MPa}$. 
In the first case there is the result of fatigue limit 304.1 MPa with region A containing steps number 1 to 7 and region $B$ steps number 8 to 23. In the second case there is the result of fatigue limit $314.1 \mathrm{MPa}$ with region $A$ containing steps number 1 to 8 and region $B$ steps number 9 to 23. The list of correct distribution to the regions $A$ and $B$ and from those resulting values of fatigue limits for both samples is summarized in table 1.

Table 1. Results of fatigue limit evaluated with $1 D$ thermographic method on both samples.

\begin{tabular}{|c|c|c|c|c|c|c|}
\hline \multirow{2}{*}{$\begin{array}{c}\text { Sample } \\
\text { nr. }\end{array}$} & \multicolumn{2}{|c|}{ Region A } & \multicolumn{2}{|c|}{ Region B } & \multirow{2}{*}{$\begin{array}{l}\text { Fatigue limit } \\
(\mathrm{MPa})\end{array}$} & \multirow{2}{*}{$\begin{array}{l}\text { Result value - } \\
\text { average (MPa) }\end{array}$} \\
\hline & from step \# & to step \# & from step \# & to step \# & & \\
\hline \multirow{4}{*}{1} & \multirow{2}{*}{1 (127.3 MPa) } & $7(280.1 \mathrm{MPa})$ & 8 (305.6 MPa) & \multirow{4}{*}{23 (687.5 MPa) } & 304.1 & \multirow{2}{*}{309.1} \\
\hline & & $8(305.6 \mathrm{MPa})$ & 9 (331.0 MPa) & & 314.1 & \\
\hline & \multirow{2}{*}{11 (382.0 MPa) } & $16(509.3 \mathrm{MPa})$ & $17(534.8 \mathrm{MPa})$ & & 516.8 & \multirow{2}{*}{529.8} \\
\hline & & $17(534.8 \mathrm{MPa})$ & $18(560.2 \mathrm{MPa})$ & & 542.8 & \\
\hline \multirow{3}{*}{2} & \multirow{3}{*}{1 (382.0 MPa) } & $4(458.4 \mathrm{MPa})$ & 5 (483.8 MPa) & \multirow{3}{*}{$13(687.5 \mathrm{MPa})$} & 470.0 & \multirow{3}{*}{494.9} \\
\hline & & $5(483.8 \mathrm{MPa})$ & 6 (509.3 MPa) & & 493.9 & \\
\hline & & $6(509.3 \mathrm{MPa})$ & 7 (534.8 MPa) & & 520.7 & \\
\hline
\end{tabular}

The measurement of sample number 2 started with the load of $382 \mathrm{MPa}$ corresponding to the set force of $30 \mathrm{kN}$, so the results around $300 \mathrm{MPa}$ as for sample 1 cannot be reached. But the evaluation of sample 1 can be started with the same beginning load as sample 2. Then it gives very similar results (around $500 \mathrm{MPa}$ ) as partial results for sample 2. This value is more realistic and is in agreement with fatigue limit estimated with standard method.

The 2D evaluation means that the procedure used in 1D variant described above is used for all pixels of sample body (thousands of pixels). So it gives the same difficulties as in 1D, especially ambiguity of first step of evaluation for sample 1 and the possibility of more than one result of fatigue limit - the condition of distribution into region $A$ and $B$ fulfils more than one distribution. The evaluation in $2 D$ is made in the same regions as for $1 D$, so for sample 1 from step number 11 to step number 23 and for sample 2 from step number 1 to step 13. The results of 2D evaluation are shown in figure 7 in the manner that each pixel of sample body introduces average value from partial results that fulfil the condition of distribution into regions $A$ and $B .2 D$ figure of minimal or maximal fatigue limit values can be obtained for pixels, where more than one partial result exists, too.

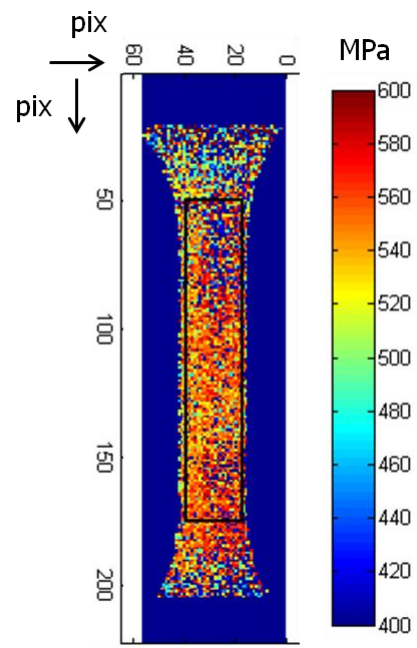

Fig. 7: Results of 2D fatigue limit evaluation of sample 1 from step 11 to step 23.

The 2D graphical presentation of each pixel average fatigue limit for sample 1 (figure 7 ) reach values from $420 \mathrm{MPa}$ to almost $600 \mathrm{MPa}$ with small areas where the fatigue limit is near to $400 \mathrm{MPa}$. The picture of sample looks quite inhomogeneous; the central part of sample body was evaluated with average fatigue limit values from 540 to $580 \mathrm{MPa}$.

The results of all methods (standard method using Wöhler curve and 1D and 2D thermographic methods) are summarized in table 2 .

Table 2. Summary of fatigue limit results evaluated using different methods.

\begin{tabular}{|l|c|c|}
\hline Method / Sample nr. & Sample 1 & Sample 2 \\
\hline Standard - Wöhler & \multicolumn{2}{|c|}{$464 \mathrm{MPa}$} \\
\hline 1D thermographic & $529.8 \pm 13.0 \mathrm{MPa}$ & $494.9 \pm 20.7 \mathrm{MPa}$ \\
\hline 2D thermographic & $556.9 \pm 12.6 \mathrm{MPa}$ & $516.0 \pm 10.5 \mathrm{MPa}$ \\
\hline
\end{tabular}


The results of thermographic methods are higher than standard method result. For sample 1 the difference exceeds $50 \mathrm{MPa}$ while results for sample 2 are in $10 \%$ tolerance to the standard method result. Results of thermographic method are comparative each other within the same sample, between samples the sample 1 reports higher fatigue limit than sample 2.

\section{Conclusions}

Thermographic measurement was used for two samples fatigue limit estimation during cyclic loading. The presented experimental setup includes except of IR camera a thermographic software module for online fatigue limit evaluation (1D analysis).

Fatigue limit was evaluated with three methods - standard method and thermographic methods in 1D and 2D version that was introduced in this contribution as an extension of $1 \mathrm{D}$ method. The results of fatigue limit estimation via thermographic measurement were compared with standard method result with good accordance. The 2D evaluation as well as 1D evaluation was in the best accordance with the standard fatigue evaluation of the second sample. The results for sample 1 are higher than standard method result. The 2D thermographic method of fatigue limit evaluation brings a pixel view to the whole sample fatigue limit testing.

\section{Acknowledgements}

The work has been supported by the Technology Agency of the Czech Republic within the project no. TE01020068 and by the Ministry of Education, Youth and Sports of the Czech Republic within the OP RDI program, CENTEM project, no. CZ.1.05/2.1.00/03.0088, co-funded by the ERDF; and National Sustainability Programme I., CENTEM PLUS project, no. LO1402.

\section{REFERENCES}

[1] F. C. Campbell, Fatigue and fracture: understanding the basics. ASM International, 2012

[2] A. L. Geraci, G. La Rosa, and R. Antonino, "Determination of the fatigue limit of an austempered ductile iron using thermal infrared imagery," in Proc. SPIE 2646, Digital Photogrammetry and Remote Sensing '95, 1995, vol. 2646, pp. 306-317.

[3] A. E. Morabito, V. Dattoma, and U. Galietti, "Energy analysis of fatigue damage by thermographic technique," Thermosense XXIV, International Society for Optical Engineering, vol. 4710, pp. 456-463, 2002.

[4] G. La Rosa and A. Risitano, "Thermographic methodology for rapid determination of the fatigue limit of materials and mechanical components," International Journal of Fatigue, vol. 22, no. 1, pp. 65-73, 2000.

[5] A. L. Geraci, A. Risitano, and G. L. A. Rosa, "Influence of frequency and cumulative damage on the determination of the fatigue limit of materials using the thermal infrared methodology," in XV Sympozjum Mechaniki Eksperymentalnej, Jachranka, 1992, pp. 63-66.

[6] P. Williams, M. Liakat, M. M. Khonsari, and O. M. Kabir, "A thermographic method for remaining fatigue life prediction of welded joints," Materials and Design, vol. 51, pp. 916-923, 2013.

[7] G. La Rosa and A. Risitano, "Application of a new methodology to determine the fatigue limit using thermal infrared techniques," in 17th Symposium on Experimental Mechanics of Solids, Jachranka, 1996, vol. 19, pp. 498-503.

[8] M. P. Luong, "Fatigue limit evaluation of metals using an infrared thermographic technique," Mechanics of Materials, vol. 28, no. 1-4, pp. 155-163, 1998.

[9] M. P. Luong, "Infrared thermographic scanning of fatigue in metals," Nuclear Engineering and Design, vol. 158, no. 2-3, pp. 363-376, 1995.

[10] A. Lipski, "Accelerated determination of the fatigue limit and the $s-n$ curve by means of the thermographic method for x5crni18-10 steel," Acta Mechanica et Automatica, vol. 10, no. 1, pp. 22-27, 2016.

[11] H. Wang, R. B. Dinwiddie, L. Jiang, P. K. Liaw, C. R. Brooks, and D. L. Klarstrom, "Application of high-speed IR imaging during mechanical fatigue tests," Thermosense XXII, April 24, 2000 - April 27, vol. 4020, no. 865, pp. 186-193, 2000.

[12] R. De Finis, D. Palumbo, F. Ancona, and U. Galietti, "Fatigue limit evaluation of various martensitic stainless steels with new robust thermographic data analysis," International Journal of Fatigue, vol. 74, pp. 88-96, 2015.

[13] L. Xiao-qing, Z. Hong-xia, Y. Zhi-feng, W. Wen-xian, Z. Ya-guo, and Z. Qian-ming, "Fatigue life prediction of AZ31B magnesium alloy and its welding joint through infrared thermography," Theoretical and Applied Fracture Mechanics, vol. 66-67, pp. 46-52, 2013.

[14] D. Palumbo and U. Galietti, "Characterisation of steel welded joints by infrared thermographic methods," Quantitative InfraRed Thermography Journal, vol. 11, no. 1, pp. 29-42, 2014.

[15] J. Tesař, J. Skála, M. Švantner, and M. Novák, "Online evaluation of material fatigue limit using infrared thermography," in METAL 2017 - 26th International Conference on Metallurgy and Materials, Conference Proceedings, 2017.

[16] "A thermographic paint for IR camera measurement - for common applications | LabIR®." [Online]. Available: http://paints.labir.eu/paint/thermographic-paint-for-standard-applications. [Accessed: 10-Apr-2018]. 